\title{
EDITORIAL
}

\section{The new era of autoimmune disease research}

\author{
Takao Koike* \\ See related research by Lee et al., http://arthritis-research.com/content/13/2/R63
}

\begin{abstract}
Recent genome-wide association studies have advanced our understanding of genetic factors that underlie systemic lupus erythematosus (SLE), a multifactorial autoimmune disease characterized by various clinical manifestations. SLE also has an environmental component, which can trigger or exacerbate the disease. Despite extensive efforts aimed at elucidating the cellular and biological abnormalities that arise in the immune system of patients with SLE, its pathology remains unclear. Lee and colleagues recently carried out gene expression profiling of patients with SLE followed by bioinformatics analysis and discovered the existence of abnormal regulatory networks and potential key molecules. The authors found that ATP synthesis and DNA repair pathways may be involved in the pathogenesis, providing a potential explanation for photosensitivity experienced by patients with SLE.
\end{abstract}

\section{Microarray and bioinformatics analyses}

Microarray analysis and gene expression profiling allow patterns of gene expression in diseases and developmental processes to be assessed. Advances in biological databases have enabled the large-scale expression profiling data to be processed and the foundation for biological interpretation to be laid. Despite this, a major limitation involves the interpretation of massive amounts of microarray data. In microarray analysis, which is often used to identify differentially expressed genes, genes that are expressed at higher or lower levels than controls are of interest. In the previous issue of Arthritis Research \& Therapy, Lee and colleagues [1] conducted gene expression and bioinformatics analyses between healthy individuals and patients with systemic lupus erythematosus (SLE) and provided insights into biological and

*Correspondence: tkoike@med.hokudai.ac.jp

Hokkaido University Graduate School of Medicine, N-15 W-7, Kita-ku, Sapporo, Japan functional abnormalities in SLE as well as abnormal regulatory networks. Such analyses - that is, gene ontology analysis, which is used to classify genes into functionally related gene groups, and network pathway analysis, which identifies relationships among these genes - provide an additional layer of insight that cannot be achieved by focusing on individual molecules [1].

\section{Interferon signature}

Lee and colleagues [2] previously demonstrated, by DNA microarray and bioinformatics analyses, that genes related to the immune response were differentially expressed in patients with SLE compared with healthy controls. Other studies have also reported increased expression of IFNinducible genes (that is, the 'IFN signature') in peripheral blood cells from patients with SLE [2-4]. Many groups are currently looking into pathological roles of plasmacytoid dendritic cells (pDCs) and IFN-inducible genes in SLE since pDCs are major producers of IFN- $\alpha$ [4-7]. Given that SLE is a systemic disease that influences multiple organs, Lee and colleagues [1] emphasized the importance of assessing biological and cellular abnormalities associated with SLE other than those related to the immune response. To this end, the authors revealed not only that apoptosis-related genes are upregulated but also that genes related to sensory perception and response to radiation/light were downregulated.

\section{Abnormalities in DNA repair and ATP synthesis}

Downregulated genes associated with sensory perception and response to radiation/light included ATPase/ATPase domain-containing genes, two excision repair crosscomplementing genes (ERCC2 and ERCC5), and six mitochondrial DNA (mtDNA) encoded genes: ATP synthase 6 (ATP6), cytochrome c oxidases 1 (COX1) and 3 (COX3), cytochrome b $(C Y T B)$, and NADH dehydrogenase subunits 1 (ND1) and $2(N D 2)$. ERCC2/XPD and $E R C C 5 / X P G$ are both involved in excision repair of UVinduced DNA damage. Patients with Xeroderma pigmentosum, Cockayne syndrome, or trichothiodystrophy harbor mutations in ERCC genes, and such patients exhibit photosensitivity. The process of UV-induced DNA damage repair is known to require ATP, and the main function of mitochondria is to generate ATP 
through oxidative phosphorylation. Accordingly, downregulation of ATP-dependent ERCC genes and mtDNAencoded genes implies that impaired DNA repair and ATP synthesis, or increased apoptosis, may contribute to the various manifestations of SLE. Consistent with this, a study by Fernandez and Perl [8] showed that mitochondrial hyperpolarization and ATP depletion predispose lupus $\mathrm{T}$ cells to necrosis. Via network pathway analysis, Lee and colleagues [1] demonstrated that cytokines IL-6, transforming growth factor-beta (TGF- $\beta$ ), and TNF play central roles as ATP synthesis-related molecules. Patients with SLE had significantly higher levels of TNF and IL-6, which are proinflammatory, whereas levels of the antiinflammatory cytokine TGF- $\beta$ were lower [9]. Furthermore, Pflegerl and colleagues [10] reported that epidermal loss of Jun B, which is linked to increased epidermal IL-6 secretion, is sufficient to induce an SLE phenotype in mice, and this suggests that defects in skin function may lead to systemic autoimmune diseases.

\section{Conclusions}

Lee and colleagues [1] revealed functional abnormalities in ATP synthesis and DNA repair in peripheral blood cells from patients with SLE. Further DNA microarray and bioinformatics analyses should provide interesting insights into the pathophysiology of autoimmune diseases.

\section{Abbreviations}

IFN, interferon; IL, interleukin; mtDNA, mitochondrial DNA; pDC, plasmacytoid dendritic cell; SLE, systemic lupus erythematosus; TGF- $\beta$, transforming growth factor-beta; TNF, tumor necrosis factor.

\section{Competing interests}

The author declares that he has no competing interests.
Published: 31 May 2011

\section{References}

1. Lee HM, Sugino H, Aoki C, Nishimoto N: Underexpression of mitochondrialDNA encoded ATP synthesis-related genes and DNA repair genes in systemic lupus erythematosus. Arthritis Res Ther 2011, 13:R63.

2. Lee HM, Mima T, Sugino H, Aoki C, Adachi Y, Yoshio-Hoshino N, Matsubara K, Nishimoto N: Interactions among type I and type II interferon, tumor necrosis factor, and beta-estradiol in the regulation of immune responserelated gene expressions in systemic lupus erythematosus. Arthritis Res Ther 2009, 11:R1.

3. Crow MK, Wohlgemuth J: Microarray analysis of gene expression in lupus. Arthritis Res Ther 2003, 5:279-287.

4. Bennett L, Palucka AK, Arce E, Cantrell V, Borvak J, Banchereau J, Pascual V: Interferon and granulopoiesis signatures in systemic lupus erythematosus blood. J Exp Med 2003, 197:711-723.

5. Hagberg N, Berggren O, Leonard D, Weber G, Bryceson YT, Alm GV, Eloranta ML, Rönnblom L: IFN-\{alpha\} production by plasmacytoid dendritic cells stimulated with RNA-containing immune complexes is promoted by NK cells via MIP-1 \{beta\} and LFA-1. J Immuno/ 2011, 186:5085-5094.

6. Guiducci C, Tripodo C, Gong M, Sangaletti S, Colombo MP, Coffman RL, Barrat FJ: Autoimmune skin inflammation is dependent on plasmacytoid dendritic cell activation by nucleic acids via TLR7 and TLR9. J Exp Med 2010, 207:2931-2942.

7. Tada Y, Kondo S, Aoki S, Koarada S, Inoue H, Suematsu R, Ohta A, MakTW, Nagasawa K: Interferon regulatory factor 5 is critical for the development of lupus in MRL/lpr mice. Arthritis Rheum 2011, 63:738-748.

8. Fernandez D, Perl A: Metabolic control of T cell activation and death in SLE. Autoimmun Rev 2009, 8:184-189.

9. Lee HM, Sugino H, Nishimoto N: Cytokine networks in systemic lupus erythematosus. J Biomed Biotechnol 2010, 2010:676284.

10. Pflegerl P, Vesely P, Hantusch B, Schlederer M, Zenz R, Janig E, Steiner G, Meixner A, Petzelbauer P, Wolf P, Soleiman A, Egger G, Moriggl R, Kishimoto T, Wagner EF, Kenner L: Epidermal loss of JunB leads to a SLE phenotype due to hyper IL-6 signaling. Proc Natl Acad Sci U S A 2009, 106:20423-20428.

doi:10.1186/ar3335

Cite this article as: Koike T: The new era of autoimmune disease research. Arthritis Research \& Therapy 2011, 13:113. 